\title{
Conserver mieux pour consommer loin
}

Techniques de conservation alimentaire en itinérance sportive (randonnée, alpinisme himalayen)

\section{Éric Boutroy et Bénédicte Vignal}

\section{(2) OpenEdition}

12 Journals

Édition électronique

URL : https://journals.openedition.org/tc/8990

DOI : $10.4000 /$ tc. 8990

ISSN : 1952-420X

Éditeur

Éditions de l'EHESS

\section{Édition imprimée}

Date de publication : 17 mai 2018

Pagination : 202-205

ISBN : 978-2-7132-2750-9

ISSN : 0248-6016

\section{Référence électronique}

Éric Boutroy et Bénédicte Vignal, «Conserver mieux pour consommer loin », Techniques \& Culture [En ligne], 69 | 2018, mis en ligne le 17 mai 2020, consulté le 29 septembre 2022. URL : http:// journals.openedition.org/tc/8990; DOI : https://doi.org/10.4000/tc.8990 


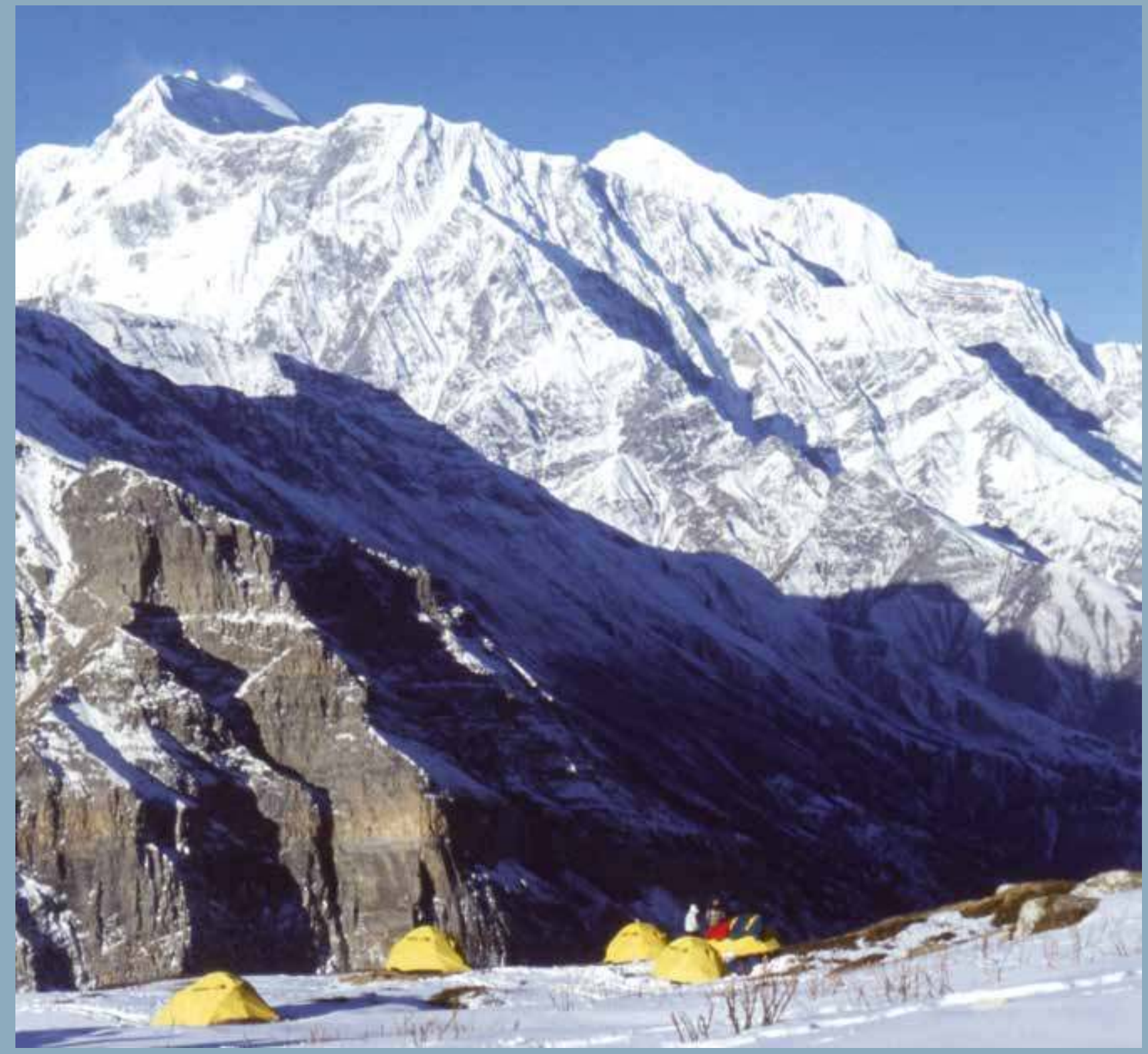




\section{Conserver mieux pour consommer loin}

\section{Techniques de conservation alimentaire en itinérance sportive (randonnée, alpinisme himalayen)}

L'itinérance sportive en espace naturel (expédition, trekking, randonnée) s'est fortement développée ces dernières décennies. Depuis les cimes himalayennes où des dizaines de milliers d'himalayistes tentent d'atteindre un culmen terrestre jusqu'aux forêts, montagnes ou déserts traversés par des millions de randonneurs itinérants (1,5 million d'adeptes en France), la problématique de la conservation alimentaire lorsque le mangeur se déplace prend des formes originales. Randonner ou grimper dans des milieux sauvages, affrontés volontairement, implique de (sur)vivre et se déplacer de quelques jours à plusieurs semaines dans un environnement isolé. Dans des contraintes environnementales fortes (chaleur/froid excessifs, humidité, altitude, contamination, souillure), les pratiquants se démunissent des systèmes sociotechniques usuels de conservation alimentaire (chaîne du froid, approvisionnement permanent, habitat sédentaire). Le système culinaire (Mahias 1985) et les procédés de conservation alimentaire recouvrent alors des enjeux considérables. Certains sont fonctionnels: transportabilité et allègement; qualité sanitaire, durabilité et protection des rations; diététique et nutrition de l'effort. D’autres enjeux sont plus fortement spécifiés culturellement (Poulain 2002) : appétence, plaisir et goût; rapports sociaux (commensalité autour du partage d'un mets «trésor ») ou distinctifs (partisans et adversaires des «lyophilisés»); aspects symboliques (aliment sain ou souillé).

L'itinérance sportive recouvre des formes et logiques de pratique différentes qui vont reconfigurer ces enjeux. À un stade exploratoire du travail, nous suggérons une opposition idéal-typique entre «minimalistes» et «consuméristes» fondée sur des correspondances entre le système culinaire et d'autres éléments de l'organisation matérielle et sociale (valeurs, rapports sociaux, organisation du travail, techniques sportives ou d'habitat - Boutroy 2011) ${ }^{1}$. Sur un versant minoritaire, les himalayistes partisans d'un «style alpin » (expéditions dites «légères », centrées sur l'économie de moyens) et les adeptes d'un mouvement, la Marche Ultra-Légère (MUL), fondé sur une quête distinctive ${ }^{2}$ et radicale de l'allègement matériel. Le «minimalisme» se base sur 


\section{Avant/après}

Le reconditionnement des rations de petit-déjeuner: mélanger muesli et lait déshydraté, adapter la quantité, protéger dans une bouteille plastique recyclée. Des techniques ordinaires pour conserver/alléger/transporter le petit-déjeuner en Marche Ultra-Légère. une recherche de la simplicité et de la frugalité (dénonciation des excès technologiques ou de la marchandisation), avec une culture de l'autonomie et du partage, du bricolage (injonction au do-it-yourself) et des relations communautaires. Sur l'autre versant, les ascensions plus courantes en style himalayen (expédition dites «lourdes») ou les randonnées itinérantes plus traditionnelles. Le «consumérisme» s'y dessine en contrepoint par une consommation matérielle importante, un attrait pour les technologies et les nouveautés portées par l'industrie, une forte délégation des tâches et un individualisme (du recrutement ou des relations) plus marqué.

Les différences stylistiques peuvent se marquer en des manières divergentes de conserver et consommer tels types d'aliments: partager des astuces alimentaires sur des sites web communautaires ou acheter un voyage clé en main organisé par une agence; concevoir et optimiser ses rations ou déléguer les tâches alimentaires à un cuisinier ou un accompagnateur; conditionner dans des sachets de congélation type «ziplock» ses portions de repas ou sélectionner dans un magasin spécialisé des plats lyophilisés sophistiqués; vider des paquets de céréales ou de lait en poudre dans des bouteilles plastiques de récupération pour composer des rations ou (faire) remplir de lourds bidons étanches avec des boîtes de conserve; porter dans son sac à dos ses aliments déshydratés calibrés et reconditionnés ou faire porter par des animaux ou des porteurs des rations protégées dans des caisses; cuisiner avec un compagnon de bivouac un menu conçu ensemble ou manger seul directement dans son sachet individuel un «lyoph».

Ces traits stylistiques peuvent être appropriés de façon nuancée selon des sous-cultures matérielles. L'inventaire suggère aussi la richesse et l'imbrication des chaînes opératoires alimentaires liées à la conservation: choix d'itinéraire (déterminant contraintes du milieu ou ravitaillement); techniques du corps (grossir, jeûner); sélections d'aliments, constitution des menus et achat des matières premières; transformation des aliments (séchage, lyophilisation, conserve...); prélèvements dans le milieu... Le croisement des conditions extrêmes et labiles, des moyens à disposition des «nomades» autant que des logiques culturelles font de l'alimentation en itinérance sportive un observatoire remarquable des techniques de conservation les plus diverses: variétés des matières premières privilégiées (de «simples» céréales aux gels énergétiques), des objets (sac, sachet, bouteille, bidon) et matériaux (papier, plastique, aluminium, verre, métal). Ces chaînes combinent des procédés industriels diversement appropriés voire 
détournés, mais aussi une créativité plus ordinaire de leurs multiples acteurs (pratiquants, encadrants, organisateurs, cuisiniers, porteurs). Dans la bigarrure de ses reconfigurations, la conservation alimentaire pour ces robinsonnades volontaires témoigne de la capacité à construire des systèmes techniques originaux dans les loisirs contemporains.

\section{En ligne}

Retrouver l'article complet sur journals.openedition.org/tc: TechniquesECulture 69 « Le temps des aliments».

\section{Notes}

1. Le «minimalisme» reprend une catégorie émique revendiquée assez explicitement par ses partisans. Le «consumérisme» est par contre une catégorisation étique qui exprime par contraste certains traits saillants de formes de consommation plus standards des pratiquants traditionnels. Elle ne renvoie pas à une aliénation ou passivité des consommateurs dont les techniques

d'usages et de détournement ne sont plus à démontrer (Julien \& Rosselin 2005) et n'empêche pas des formes régulées de «consumérisme politique» (Cochoy 2008): tourisme responsable, labels éthiques...

2. Les «mulistes» brocardent par exemple les «MULETs» (Marcheurs Ultra-Lourds Et Têtus)... qu'ils reconnaissent avoir été.

\section{Iconographie}

Image d'ouverture. Vivre isolé dans un milieu sauvage: un camp de base d'expédition himalayenne. À 4500 mètres dans le massif des Annapurnas (Népal), le camp de base implique de conserver la nourriture et de

se nourrir en autonomie dans un environnement extrême (isolement, altitude, froid, vent...). (CÉric Boutroy.

1. (C) Magazine Carnets d'Aventures

\section{Les auteurs}

Éric Boutroy est ethnologue, enseignant-chercheur au sein du laboratoire sur les vulnérabilités et l'innovation dans le sport (L-ViS, EA 7428, Université Lyon 1), ses recherches portent sur les cultures sportives, l'innovation et l'accidentologie dans les sports de nature; à ses heures perdues, adepte un peu trop « mulet » d'itinérances montagnardes. Bénédicte Vignal est sociologue, maître de conférences en sciences et techniques des activités physiques et sportives. Ses travaux au sein du L-ViS (EA 7428, Université Lyon 1) portent sur les formes de pratiques sportives, les logiques de consommation et les innovations dans le secteur de l'outdoor.

\section{Références}

Boutroy, E. 2011 «Habiter une nature extrême. Approche sémio-technologique de la tente d'expédition», in G. Raveneau \& O. Sirost dir. Anthropologie des abris de loisir. Paris: Presses Universitaires de Paris 10: 153-166.

Cochoy, F. 2008 «Faut-il abandonner la politique aux marchés? Réflexions autour de la consommation engagée», Revue Française de Socio-Économie 1(1): 107-129.
Julien, M.-P. \& C. Rosselin 2005 La culture matérielle. Paris: La Découverte.

Mahias, M.-C. 1985 Délivrance et convivialité: Le système culinaire des Jaina. Paris: Éditions de la MSH.

Poulain, J.-P. 2002 Sociologies de l'alimentation. Les mangeurs et l'espace ordinaire. Paris: Presses Universitaires de France.

\section{Pour citer l'article}

Boutroy, E. \& B. Vignal 2018 «Conserver mieux pour consommer loin. Techniques de conservation alimentaire en itinérance sportive (randonnée, alpinisme himalayen)», TechniquesE Culture 69 « Le temps des aliments », p. 202-205. 